\title{
REDES SOCIAIS CORPORATIVAS APLICADAS À GESTÃO ESTRATÉGICA DE PESSOAS: DESAFIOS DE UMA NOVA FERRAMENTA
}

\section{ARTIGO ORIGINAL}

SILVA, Marina Reis Dos Santos ${ }^{1}$

REBELLO, Patrícia ${ }^{2}$

SILVA, Marina Reis Dos Santos. REBELLO, Patrícia. Redes sociais corporativas aplicadas à gestão estratégica de pessoas: Desafios de uma nova ferramenta. Revista Científica Multidisciplinar Núcleo do Conhecimento. Ano 05, Ed. 07, Vol. 04, pp. 89-122. Julho de 2020. ISSN: 2448-0959, Link de acesso: https://www.nucleodoconhecimento.com.br/comunicacao/redes-sociaiscorporativas

\section{RESUMO}

Este estudo objetivou entender quais motivos fazem com que uma rede social corporativa, enquanto ferramenta da comunicação interna, se torne impopular entre gestores executivos e profissionais, bem como investigar os conceitos e teorias das áreas de comunicação interna, cultura organizacional, e gestão estratégica, que permeiam a temática; e refletir sobre as necessidades de uma nova geração de funcionários acostumados à constante presença da tecnologia em seus cotidianos. Para tanto, foi utilizado como método para coleta de dados a pesquisa bibliográfica,

\footnotetext{
${ }^{1}$ Especialista (MBA) em Gestão Estratégica de Marketing, Planejamento e Inteligência Competitiva, Bacharel em Comunicação Social com habilitação em Relações Públicas.

2 Doutorado em Comunicação. Mestrado em Comunicação. Graduação em Jornalismo. Graduação em Relações Públicas.
} 
através do estudo levantado no embasamento teórico, e o estudo de dois casos específicos. A partir da análise de dados foi possível perceber a importância da utilização de ferramentas digitais atuais e as limitações organizacionais nos processos de implantação. Enfim, por meio de todo o estudo realizado e dos fatos apresentados foi possível verificar os desafios enfrentados e dar relevo aos pontos que podem ser modificados.

Palavras-chave: Cultura organizacional, comunicação interna, gestão estratégica, geração internet, redes sociais corporativas.

\section{INTRODUÇÃO}

É muito comum a utilização de ferramentas específicas nas atividades de comunicação corporativa com o propósito de estabelecer e manter um fluxo contínuo de informações para os seus públicos de interesse - parceiros de negócios, colaboradores, consumidores e quaisquer outros grupos que se relacionem de alguma forma com a organização e necessitem manterem-se atualizados sobre suas ações.

Na comunicação interna, área responsável pelo planejamento e execução de ações de relacionamento com o público interno de uma empresa, é possível notar a presença de diferentes tipos de instrumentos, dos mais tradicionais, como os canais impressos e eventos corporativos, até os mais modernos, que se utilizam de veículos digitais, como os sistemas de intranet e redes sociais virtuais.

Numa escala global, as ferramentas digitais são cada vez mais utilizadas a fim de possibilitar o compartilhamento rápido de notícias nos mais variados ambientes e promover a participação social e a colaboração mútua entre as pessoas. As mudanças alcançadas pelas evoluções da web permitem ao usuário não só receber informações como também ser difusor da mensagem e emissor de opinião, abandonando a antiga postura passiva de mero consumidor de informações.

Avaliando a importância das redes digitais na sociedade e o modo como diferentes gerações interagem entre si em seus universos sociais por meio dela, qual seria a 
utilidade de uma rede social interna em um ambiente corporativo? Entre as possibilidades, permitir que seus próprios usuários funcionem como emissores, agilizando processos, incentivando o desenvolvimento de ideias e promovendo a quebra de barreiras nas organizações ao estabelecer um sistema de comunicação horizontal. Considerando o novo panorama social, esta pesquisa desenvolve-se em torno das questões sobre como os processos de gestão de pessoas estão se preparando para lidar com funcionários inseridos num universo digital.

Observa-se que nos dias de hoje a internet é um elemento cada vez mais presente na vida dos indivíduos e usada para os mais diversos fins, dentre eles a comunicação e troca de informações. Ao considerar seu histórico de evolução, partindo-se da premissa de que esta utilização cresce e apresenta sempre novas funções, seja por meio de aplicativos desenvolvidos ou redes sociais, trata-se de uma ferramenta que apresenta benefícios aos usuários, com uso não somente em múltiplas funções, mas também em múltiplos ambientes, como, por exemplo, os de trabalho. Se bem empregada e utilizada em uma organização, a comunicação por meio da internet pode agilizar processos e desenvolver formas de interação entre funcionários que venham a favorecer a troca de conteúdos referentes às suas funções e ao desempenho das mesmas.

Para decifrar os fenômenos investigados, esta monografia objetivou entender quais motivos fazem com que uma rede social corporativa se torne impopular entre gestores executivos e profissionais da área enquanto ferramenta da comunicação interna. Além disso, busca investigar os conceitos e teorias das áreas de Comunicação Interna e Cultura organizacional que permeiam a temática. O intuito é pensar a comunicação organizacional e as necessidades de uma nova geração de funcionários acostumados à constante presença da tecnologia em seus cotidianos.

A escolha deste tema como objeto de pesquisa ocorreu através da identificação, por meio de experiências com membros integrantes das equipes de comunicação das instituições especificadas nos casos, de posicionamentos relutantes e questionamentos em relação à implantação de mídias digitais com características 
bastante similares às redes sociais corporativas - bem diferentes da ferramenta digital de utilização bastante comum nas áreas de comunicação interna, a intranet.

A proposta básica da rede social interna é favorecer a interação entre os funcionários da empresa facilitando também os processos de trabalho nos quais estes se encontram envolvidos e a troca de conteúdos em relação às suas tarefas. Conforme explica Terra (2009), a transformação do usuário em agente implica em riscos e apostas no acaso das circunstâncias, bem como nas situações posteriormente exemplificadas que assustam os gestores e funcionários pelo receio de lidar com respostas negativas a alguma proposta.

Acredita-se que a melhor maneira para abordar a temática é recorrendo aos fundamentos teóricos de autores especialistas das áreas para só então unificar e confrontar tais ideias. O tipo de pesquisa escolhida é o estudo de caso, um método qualitativo destinado à compreensão de questionamentos sobre determinados fenômenos a partir da observação do espaço e de seus acontecimentos.

Esta estratégia de pesquisa almeja produzir um estudo empírico que busca a introdução de informações preliminares sobre o posicionamento organizacional quanto a utilização da ferramenta de comunicação proposta. A descrição dos acontecimentos pretende também problematizar os panoramas, inclusive confrontando teorias já existentes com novas e iniciando uma discussão sobre o fenômeno que servirá para futuras investigações num mestrado profissional em Gestão Estratégica e Negócios.

Foram consultadas nesta pesquisa pessoas cujas atuações mostraram-se essenciais para o resultado final no que diz respeito ao posicionamento da organização diante dos fenômenos. Tais atores, funcionários das empresas citadas, são responsáveis pelas consequências do processo aqui exposto.

Por se tratar de um estudo de casos, é conveniente antecipar possíveis críticas informando certas limitações que surgiram, como o fato de que os dados apresentados são observações realizadas durante o período de estágio da autora do 
trabalho, e que, para evitar constrangimentos e/ou possíveis problemas judiciais/administrativos, a caracterização das empresas evita nomes específicos, tanto das organizações quanto de seus funcionários. Todavia, os pontos especificados não invalidam a realização da pesquisa. Por último, considera-se que este estudo possibilitará uma reflexão sobre as necessidades de uma nova geração de colaboradores comparadas aos que já são ofertados.

Na pesquisa em questão, a proposta é investigar processos organizacionais baseados na interpretação de dois casos, investigando e analisando-os à luz do referencial teórico. Em ambos os casos, há indisposição para os riscos da parte, uma vez que, por receio, os responsáveis optam por não executarem as propostas.

No primeiro caso, a empresa, aqui denominada $A$, é uma indústria fabril de equipamentos pesados que precisam de lidar com limitações estruturais de equipe. Enquanto isso, o segundo caso, chamada de empresa $\mathrm{B}$, corresponde a um instituto de apoio ao controle e prevenção na área da saúde cuja equipe responsável pelo processo de comunicação interna vê-se recentemente envolvida com a possibilidade de lidar com uma nova ferramenta digital.

\section{PERCURSOS TEÓRICOS}

\subsection{SOCIEDADE E REDES}

Apesar da facilidade em encontrar bibliografias bastante específicas para as áreas de gestão de pessoas, comunicação interna, e cultura organizacional, não é incomum deparar-se com tais áreas interligadas, colocando em prática parte significativa das ações estratégicas de uma organização - o que por sua vez reforça a necessidade de uma pesquisa sobre a temática.

É possível constatar nas teorias sobre os impactos tecnológicos na sociedade, idealizadas por Manuel Castells (1999), referências para explicar como as relações humanas acontecem no plano da revolução da tecnologia da informação e no processo de globalização. A sociedade está cada vez mais envolvida com as novas 
tecnologias, e a maneira como o autor enfoca o assunto permite enxergar como ela vem revolucionando a forma de pensar e agir.

Para Castells (1999), as maneiras como as relações se processam vêm sofrendo transformações gradativas mediante 0 uso de dispositivos tecnológicos que proporcionam maior interatividade entre os indivíduos ou facilitam o relacionamento em rede existente até então. As possibilidades de interação proporcionadas pela internet alteram a maneira e o tempo como as informações chegam até os indivíduos gerando impacto e influências cada vez mais elevados.

Em paralelo, esta facilidade de acesso a conteúdos e pessoas através da internet arregimenta um número cada vez maior de usuários. Para este autor, essa alteração instrumental na comunicação interfere também em questões de âmbito social e psicológico presentes na vida humana alterando-as. Além disso, ao considerar que o ato de se comunicar é algo complexo que envolve históricos pessoais e interpretações diversas e/ou difusas, a possibilidade de influência exercida por esta troca de informações torna-se ainda mais delicada.

Essa metamorfose social viabiliza uma sociedade habituada a receber impactos informacionais, chamada de nova sociedade em rede, que busca um novo formato interfaceada por tecnologias digitais que por sua vez terminam por culminar em uma cultura da virtualidade, determinando mudanças significativas nas formas de circulação da informação.

Muniz Sodré (2002) também analisa a sociedade sob a ótica de uma nova qualificação de vida: uma bios virtual, onde a midiatização converge à socialização. Essa nova visão das coisas no mundo é uma característica da modernidade. O autor afirma que, a partir do computador, vive-se uma cultura de simulação - um espelho midiático estruturando uma nova realidade através das relações estabelecidas e que se fundamentam em uma representação apresentativa. As redes são onde as conexões e as interseções acontecem e a comunicação é o plano sistêmico da estrutura do poder. 
A sociedade contemporânea segundo Sodré (2002) rege-se pela tendência à virtualização das relações humanas. $O$ autor disserta acerca de um espelho midiático com um novo espaço e outros parâmetros para a constituição das identidades pessoais.

A midiatização deve ser pensada como uma tecnologia de sociabilidade em que predomina a esfera dos negócios com uma qualificação cultural própria que remete à evolução sem que se perca a essência do ato de comunicar. Nesse sentido, o que se mostrava habitual até o momento, altera-se com base nos novos parâmetros tecnológicos e sofre interferência direta da natureza informacional, conforme explica Sodré (2002).

Portanto, constroem-se novas relações a partir das possibilidades de dinamismo acarretadas à comunicação. Ponto interessante levantado na obra é o fato de que apesar das novas variáveis técnicas, econômicas e políticas, as transformações tecnológicas da informação apresentam-se francamente conservadoras das velhas estruturas de poder, que serão discutidas nos casos escolhidos para este trabalho.

Sodré fala ainda sobre as formas que estruturam uma cultura, até a ação do homem dentro da sociedade alicerça base para reflexão do processo comunicacional e como esse processo é afetado pela abertura do espaço virtual.

Destaca também a forma como a ideia de espaço horizontal está comprometida pelos valores representativos e introduz a Hexis - "A possibilidade de instalação da diferença na imposição estaticamente identitária do ethos" (SODRÉ, 2002, p.84). Nesta premissa, o que era da ordem do espaço público torna-se elemento do espaço virtual. Ou seja, informação e/ou conteúdos a serem acompanhados e/ou compartilhados de forma rápida por indivíduos através de um computador ou outro dispositivo tecnológico que desempenhe a mesma função.

Assim como Castells (1999) também dá conta de um envolvimento provocado pelas mídias eletrônicas, as teorias desenvolvidas por Muniz Sodré (2002) seguem 
utilizando uma argumentação antropológica sobre o cenário onde agora se constituem e movimentam os novos sujeitos sociais moldados pelo cenário virtual.

Faz-se relevante também, para vias de embasamento teórico deste estudo, as observações de Tapscott (2010), em obra em que o autor assevera a relevância da internet para a sociedade mais jovem. Segundo sua ótica, os jovens que nos dias de hoje usam a internet com frequência, levam, consequentemente, esta experiência para os mais variados setores de suas vidas. Isso interfere diretamente no funcionamento das organizações, atribuindo-Ihes caráter inovador e moderno. $O$ autor classifica tais jovens como "geração digital", e destaca que, para eles, a internet é algo que, por estar sempre presente, ou seja, por ser utilizada com frequência, tornou-se algo natural.

Segundo o autor, certas características destes jovens destacam-se neste contexto: liberdade de escolha; tendência para customização; postura investigativa; defesa da integridade da empresas e postura responsável como consumidores; valorização do lúdico e do entretenimento também no trabalho; atitude de colaboração e culto aos relacionamentos; exigência de velocidade e rapidez nas respostas; busca da inovação.

Cabe ressaltar que estas características são levantadas em comparação às gerações anteriores, ou seja, os jovens dispõem daquilo que faltou aos seus pais. Não há como não considerar esta perspectiva como um avanço, como modernização.

Para Tapscott (2010), considerando os indivíduos que frequentemente utilizam a internet, há críticas que remetem às inovações propostas por estas gerações, conforme pode ser observado na afirmativa:

A maioria das críticas se baseia em desconfiança e medo, geralmente por parte de pessoas mais velhas. Esses temores talvez sejam compreensíveis. A nova rede, nas mãos de uma nova Geração Internet tecnologicamente preparada e com uma mentalidade comunitária, tem o poder de abalar a sociedade e derrubar autoridades em várias áreas. Quando a informação flui livremente e as pessoas têm as ferramentas

Disponível em: https://www.nucleodoconhecimento.com.br/comunicacao/redes-sociais- 
para compartilhá-la de maneira eficaz e usá-la para se organizar, a vida como nós a conhecemos se torna diferente. (TAPSCOTT, 2010, p. 17).

O autor caracteriza o processo de digitalização dos meios como elemento capaz de alterar a sociedade. O receio de que tais abalos se configurem, remete, muitas das vezes, à não aceitação e possibilidades associadas à rede digital: por medo de resultados, opta-se pela não aceitação.

Não há como negar as transformações que estes jovens da Geração Digital, segundo denominação utilizada por Tapscott (2010), têm plena capacidade de transformar as organizações. Porém, estas transformações podem representar, sob a ótica de gestores, problemas ou situações trabalhosas das quais se desconhecem resultados.

As organizações, por desconhecerem os desdobramentos e impactos sugeridos pelas mudanças, nem sempre apresentam disposição para encarar os desafios propostos pela Geração Digitalde Tapscott (2010). Entretanto, frente à modernidade, esta transição acaba por tornar-se necessária para que se possa acompanhar comportamentos e valores da sociedade, consequentemente mantendo-se uma atuação favorável.

O meio virtual não é apenas uma esfera onde se buscam informações, mas também um local em que conhecimentos e iniciativas são compartilhados e a troca faz-se efetiva tendo como fim a comunicação. Partindo da premissa do autor de que através da internet, mais especificamente através das redes sociais, comunidades são unidas em torno de causa(s) específica(s), convém às organizações entender que proporcionar união semelhante entre seus funcionários, em prol de causas que sejam de interesse da organização, pode ser proveitoso.

Tapscott (2010) aponta que as mobilizações virtuais agem como elementos de mudança nos padrões de comportamento. Neste contexto, é conveniente que as organizações usem tal possibilidade em seu favor, ou seja, adaptem ferramentas tecnológicas para que o padrão de comportamento de seus funcionários seja alterado 
em favor da própria organização e, além disso, para que os processos de trabalho, bem como a qualidade de vida em ambiente organizacional, sejam favorecidos.

\subsection{ORGANIZAÇÕES E TECNOLOGIAS}

Durante muitos anos, a comunicação empresarial foi definida como aquela voltada para atender à hierarquia, controle de procedimentos e comportamentos padrões que constavam nos manuais elaborados por engenheiros. A comunicação interna nessas organizações limitava-se a atender os interesses organizacionais e informar os diversos segmentos do público interno (diretoria, gerências e funcionários), conforme descreve Guedes (2008):

Assim como as sociedades $e$ as organizações retratam as características de cada momento histórico e sofrem os impactos da evolução das tecnologias, as formas de comunicação também foram adquirindo novos contornos, consoantes com a evolução da sociedade, das organizações, das teorias organizacionais e das teorias da comunicação. [...] A Teoria Científica de Taylor, focada nas tarefas individuais, e a Teoria Clássica de Fayol, com ênfase na estrutura (departamentalização), cujas características são encontradas nas organizações tradicionais, geraram um sistema de comunicação orientado para atender à hierarquia rígida [...] Era uma comunicação formal, burocrática, transmissora de mensagens no sentido hierárquico descendente e de mão única. (GUEDES, 2008, p. 47).

Atualmente, pode-se interpretar a comunicação interna como um conjunto de ações coordenadas que tem por objetivo informar, mobilizar, educar e manter a coesão interna referente aos valores que precisam ser reconhecidos e compartilhados por todos os públicos interessantes à organização e que podem contribuir para a construção de boa imagem pública.

A comunicação no interior das organizações ocorre por meio de fluxos identificados por Curvello (2012) como: fluxo ascendente, fluxo descendente, fluxo horizontal e, com o advento de tecnologias como o e-mail, as intranets e até mesmo as redes sociais corporativas, o fluxo transversal.

Disponível em: https://www.nucleodoconhecimento.com.br/comunicacao/redes-sociais- 
Entre os fluxos, relacionados aos assuntos tratados nesta pesquisa destacam-se o fluxo descendente, aquele que compreende as informações que se originam nos altos escalões e são transmitidas aos funcionários, por meio de inúmeros canais, o mais comum, e o fluxo transversal, que teria "o poder de subverter as hierarquias, ao permitir a transmissão de mensagens entre funcionários de diferentes setores e/ou departamentos e mesmo entre níveis hierárquicos diferentes, sobretudo no contexto de projetos e programas interdepartamentais." (CURVELLO, 2012, p. 23-24).

Cabe ainda balizar que redes sociais internas, no conceito utilizado nesta pesquisa, compreendem a comunicação entre pessoas no formato de redes, e que seja digital, ou seja, semelhantes aos modelos virtuais existentes no âmbito global, isto é, em ambiente externo, mas que, por ser interna, limitam-se a este público de interesse caracterizado nos conceitos anteriores.

É de extrema importância rever o estudo de Margarida Kunsch (2007) desenvolvido no artigo "Comunicação Organizacional na era digital: contextos, percursos e possibilidades" no qual afirma:

Situar a sociedade onde estamos inseridos constitui condição sine qua non

para análises de cenários e contextos, cujas leituras são obj eto de interpretações para construção de diagnósticos situacionais e constituem subsídios indispensáveis no processo do planejamento e da gestão estratégica da comunicação corporativa (KUNSCH, 2007, p. 40).

Kunsch (2007), assim como os outros autores aqui utilizados, também identifica a influência dos avanços tecnológicos no processo comunicativo e no comportamento da sociedade e afirma que um novo ambiente social exige novos posicionamentos das organizações no relacionamento com seus públicos de interesse, além de um planejamento mais apurado, que considere implicações técnicas, éticas e morais. A autora também reconhece a realidade atual dos "cenários mutantes" regidos pelas convergências midiáticas:

É exatamente no âmbito dessa nova sociedade e de cenários mutantes e complexos que as organizações operam, lutam para se manter e para

Disponível em: https://www.nucleodoconhecimento.com.br/comunicacao/redes-sociais- 
cumprir sua missão e visão e para cultivar seus valores. A comunicação neste contexto tem um importante papel a exercer e passa a ser considerada de forma muito mais estratégica do que no passado. (KUNSCH, 2007, p. 41)

Salienta-se, portanto, a comunicação como elemento que integra a estrutura organizacional. Enquanto estratégia, trata-se de uma ação com sentido e significado fundamentados nas relações que a originam nas quais se integram e sobre a quais determinam influências. Os meios ou ferramentas empregados para esta comunicação agem, consequentemente, como intermediários técnicos destas relações sociais.

Ainda considerando este cenário de transformação, parece interessante o comentário de Cândido e Abreu (2000) que caracterizam a relação por meio de redes sociais como advento que possibilita diversas formas de integração e interação, em que os envolvidos e/ou participantes podem ser considerados parceiros. Quando bem orientada, esta situação pode favorecer as ações em prol dos objetivos organizacionais.

Contribuindo também para os estudos neste campo, a autora Carolina Terra (2009) disserta no artigo "A comunicação organizacional em tempos de redes sociais online e de usuários- mídia" propostas de atuação a partir do desenvolvimento do conceito de Usuário - Mídia, que seria um internauta que publica e colabora com as informações na rede, alterando o paradigma midiático de até então.

Para gerir esse processo de monitoramento, análise e proposição de ações, o comunicador tem de lançar mão de diversas estratégias: (...) estabelecer canais de comunicação sinceros, transparentes e ágeis com os públicos; alterar o paradigma do controle da informação e da marca; criar uma cultura interna de participação, colaboração e coletividade a fim de refletir tais princípios externamente; entender a dinâmica de funcionamento deste universo e abrir-se para uma via de entendimento. (TERRA, 2009, p. 12-13)

A obra ajuda a compreender como a mesma realidade de vida antes do advento da comunicação em rede, dominado pelos grupos de mídia e das corporações, hoje

Disponível em: https://www.nucleodoconhecimento.com.br/comunicacao/redes-sociais- 
também é de posse dos usuários de internet e como esse panorama modifica completamente a maneira de se pensar, praticar e avaliar ações de relações públicas.

Terra (2009) diz que se faz cada vez mais frequente o uso de redes sociais pelas organizações; fala também sobre como as tecnologias da informação permitiram uma inversão de poder nos processos de comunicação. A autora especifica esta por meio do argumento de que a função da comunicação de massa, antes das redes digitais, era dominada pelas grandes mídias de massa e corporações de grande porte e significativo valor de mercado. Entretanto, após o crescimento destas redes, este tipo de comunicação tornou-se realidade também para o usuário comum. As relações estabelecidas até então passaram a ser movidas em torno das pessoas e voltadas para aquilo que fosse de interesse delas.

Ainda para caracterizar essa inversão, encontra-se em Srour (1998) a análise de questões sobre poder e cultura nas organizações e de que maneira essas questões podem ser trabalhadas pelos profissionais de comunicação nos processos de relacionamento com os públicos de interesse. Segundo o autor:

As relações coletivas articulam agentes empenhados em intervenções sobre as realidades material e imaterial, tangível e intangível. Demarcam, portanto, processos de transformação da natureza e da sociedade, atividades padronizadas que constituem as práticas sociais. Milhares de exemplos podem ser pinçados no cotidiano. (SROUR,1998, p.89)

Para este autor, considerando-se o poder dentro de uma organização, este se dá em termos de relações sociais, que articulam classes e categorias, visando atingir o objetivo da própria organização. Há que se valorizar a possível mudança, visto que esta se mostra inevitável frente à modernização.

Busca-se também explicar as relações de poder, questão que será destacada nos estudos de caso escolhidos para este trabalho. O autor diz que "trabalho, mando e influência são relações sociais, esforços concertados entre agentes sociais, processos de cooperação, de emulação, de competição ou de antagonismo" (SROUR,1998, p.89).

Disponível em: https://www.nucleodoconhecimento.com.br/comunicacao/redes-sociais- 
Neste contexto, conforme será explorado nos casos apresentados neste estudo, propostas associadas à rede social interna e demais formas mais contemporâneas de comunicação entre funcionários de uma organização podem gerar divergências e, senão forem bem discutidas e avaliadas suas possibilidades, podem, em um primeiro momento, não receber a devida aceitação. Em suma, há que se investigar o motivo pelo qual uma ferramenta que deveria acrescentar, perde esta essência inovadora, adquirindo conotação negativa.

Considerando que a rotina do ambiente de trabalho apresenta riqueza de informações que se sucedem com excessiva agilidade e requerem o acompanhamento de todos os envolvidos, os processos e planejamentos de comunicação são vitais para a organização.

Dentro deste contexto, a comunicação interna exerce papel estratégico na construção de um universo simbólico para estes funcionários, que aliado às políticas de administração de recursos humanos, tem por objetivo a aproximação e integração dos públicos de interesse aos princípios e objetivos centrais da empresa. A forma como a comunicação interna se processa, e os resultados oriundos deste processo, bem como as reflexões despertadas, serão fatores relevantes ao desenvolvimento da organização e às metas ou objetivos previamente estipulados sejam atingidos.

Para exercer esse papel, a comunicação interna apropria-se dos elementos pertencentes a esse universo simbólico (histórias, mitos, heróis, rituais) na construção e veiculação das mensagens pelos canais formais (jornais, boletins, circulares, reuniões), numa permanente relação de troca com o ambiente. Sendo assim, a comunicação interna, enquanto processo específico através do qual a informação se movimenta e é trocada, é importante para o sucesso da organização. Este tipo de comunicação, ao ser bem estruturada, alicerça também a relação entre funcionários.

Atualmente, considerando todos os avanços tecnológicos nas últimas décadas, a tecnologia desempenha um papel importante na forma pela qual a informação é compartilhada e utilizada. Uma vez que o homem, conforme análise de Cândido e 
Abreu (2000), é considerado um ser eminentemente social, ferramentas e valores contemporâneos que favoreçam esta interação tendem a gerar bons resultados em âmbito também organizacional; a exploração das ferramentas em ambiente de trabalho, se bem organizada, é também possibilidade de avanço e progresso para a organização empresarial.

Ellida Neiva Guedes (2008) contribui para reflexão sobre valores contemporâneos nas organizações, principalmente na área de comunicação interna, para ela:

As transformações da contemporaneidade, refletidas em todos os campos da vida do homem, seguem o ritmo das tecnologias da informação e da comunicação (...) O indivíduo informado requer cada vez mais participação, nos contextos social e organizacional, o que vem sendo considerado nas modernas teorias de gestão e valorizado nos processos comunicacionais. (...)Busca-se, assim, "[...]um novo relacionamento em que todos são considerados parceiros, participam do negócio e procuram soluções que sejam boas para ambas as partes", dizem Oliveira e Silva (2006, p. 7). Essa é a visão que deve nortear, hoje, as políticas de comunicação das organizações. (GUEDES, 2008, p. 1)

Este universo simbólico também sofre modificações e interferências, decorrentes das constantes mudanças que acontecem fora das organizações. Ellida Guedes (2008) continua sua reflexão na obra intitulada "Já não bastam mídias, campanhas e eventos: a comunicação interna precisa construir sentido", afirmando que:

Além das influências do ambiente externo, o processo comunicacional nas organizações ampara-se nos valores, significados, símbolos, ritos, mitos e condutas - na cultura organizacional - que surgem das necessidades do empregado se adaptar às diferentes situações $e$ momentos, pois, segundo Schein (2001, p. 41), o ser humano, através da formação de culturas, trabalha para estabilizar e "normatizar" situações imprevisíveis e caóticas. Percebe- se, então, a forte associação da comunicação interna com a cultura organizacional [...]. (GUEDES, 2008, p. 2)

Segundo Guedes (2008), o fluxo natural da vida, de forma ampla, segue os rumos da tecnologia. Dentro deste contexto, a contemporaneidade é elemento que se impõe à evolução, fazendo parte dela. Para as organizações, isto não se dá de forma diferente: se uma organização busca evoluir, continuar crescendo e apresentando desempenho 
- no que se refere ao seu funcionamento - satisfatório, é preciso que se adapte ao meio, acompanhe as mudanças que este meio oferece, caso contrário tornar-se-á obsoleta.

Em paralelo, para poder acompanhar estas mudanças, há que se buscar consenso e inclusão de todos os indivíduos envolvidos no processo de transformação/modernização, sejam eles funcionários mais baixos ou de cargos mais elevados. O convívio e a troca de ideias e informações são essenciais para que este entendimento estabeleça-se de uma melhor forma, atendendo à contento os objetivos da organização e ajudando na busca pela melhor forma de transformação dentro daquilo que é primordial.

Um dos pontos chave aos quais essa transformação remete, é a tecnologia das redes sociais digitais, que podem ser elementos contundentes no processo de evolução de uma organização. Nesta premissa, Guedes (2008) enfoca as mudanças percebidas nas formas de comunicação interna das organizações a partir da década de oitenta, fator que vem de encontro à temática deste estudo e cujo funcionamento e modo de operação são cada vez mais determinados pela presença de tecnologia avançada.

Observa-se que as organizações valorizam um pouco mais a figura do funcionário e as ideias que possam surgir a partir da colaboração deste. Esta é uma proposta válida para as empresas que, nos dias atuais, buscam valorizar sua mão de obra através de processos de interatividade.

Por fim, torna-se importante observar as considerações sobre a viabilidade dos processos de mudanças organizacional através da obra de Marco Kissil[3] (1998). autor busca pensar esse processo por meio de um manual para gestores em saúde e defende que

Um dos grandes marcos do mundo contemporâneo é o fenômeno da MUDANÇA. Mudança que resulta das contínuas transformações que se dão nos campos político, econômico, tecnológico e filosófico. MUDAR passa a ser palavra de ordem para a sobrevivência organizacional. O 
setor da saúde, como qualquer outro setor, tem suas organizações que também buscam a MUDANÇA. (KISSIL, 1998, p.1)[4]

O autor tanto mostra possibilidades, quanto fala das formas de gestão de tal processo, tendo como produto final uma série de orientações para gerenciamento da mudança na área da saúde.

Apesar de ser um manual voltado para profissionais de saúde, a obra de Kissil (1998) também pode ser utilizada para pensar organizações atuantes em outras áreas, servindo para os casos aqui estudados. Conforme o autor, diversos impasses podem dificultar alterações na cultura organizacional; coexistente, há situações em que estas alterações fazem-se necessárias para que a organização possa se manter.

Algumas organizações, efetivamente, têm receio de mudanças que venham modificar 'drasticamente' sua estrutura funcional, ação que pode limitá-las em relação às outras organizações cuja aceitação em torno de mudanças seja mais ousada.

A pressão gerada pela necessidade de mudança faz com que as organizações explorem possíveis novas rotas de acesso e renovação, que venham garantir sua manutenção sem que sejam propostas, e/ou efetivas mudanças radicais, que possam comprometer o processo de comunicação como um todo.

É nesse contexto que se tangencia a questão do medo do novo, ou talvez medo de não se adaptar de imediato àquilo que surge, em princípio, como necessidade real. Ainda conforme Kissil (1998), trata-se de 'forças desestabilizadoras', ou seja, eventos que interferem no funcionamento da organização e que devem ser consideradas em sua natureza e fonte para que possam ser minimizadas e para que a organização possa, de fato, evoluir.

\subsection{CULTURA ORGANIZACIONAL E COMUNICAÇÃO INTERNA: ESTUDO DE CASOS}

\subsubsection{PODER E GESTÃO ESTRATÉGICA}

Disponível em: https://www.nucleodoconhecimento.com.br/comunicacao/redes-sociais- 


\subsubsection{EMPRESA A - DESCRIÇÃO DO CASO}

Criada na década de 1970, a empresa A nasceu com o propósito de construir equipamentos de reposição para as usinas nucleares brasileiras. Devido a indefinição do programa nuclear no Brasil, em meados da década de 2000, a empresa optou por ampliar o portfólio de produtos. Com isso, incorporou à sua produção fabril a fabricação de equipamentos pesados diversificados.

A empresa conta, em seu parque industrial, com um centro de treinamento e formação de mão de obra, que atua não só com a formação dos novos profissionais para o mercado, como também no processo de qualificação permanente de seus trabalhadores.

Pretende, de acordo com a descrição dos termos de "visão" disponível no site da organização, alcançar até 2017, o reconhecimento na área de fabricação de equipamentos e componentes pesados, além da habilidade em absorver e desenvolver novas tecnologias, principalmente nos seus segmentos de atuação fabril.

Com a constante busca pela renovação e atualização após a diversificação de seu portfólio, a alta gestão da empresa constatou a necessidade de renovar seu posicionamento e imagem no mercado, inclusive atualizando as formas e formatos de relacionamento com os públicos de interesse, surgindo, então, novas políticas de relações institucionais.

O novo plano de comunicação corporativa prevê a atualização de ferramentas já existentes e utilizadas na organização, assim como a implantação de canais e ferramentas de comunicação interna. Com toda essa mobilização, desponta de dentro das necessidades levantadas o projeto de atualização da intranet - principal plataforma de comunicação interna até aquele momento da organização e também a que mais se aproxima do conceito de mídias digitais - que deve considerar principalmente um novo layout para o canal já existente. 
O projeto da "nova intranet", elaborado em conjunto por funcionários das áreas de comunicação e de informática e apresentado para a gerência-mãe, interlocutora dos processos para a diretoria executiva, disponibilizava, sem implicar suas necessidades, um uso inédito para os empregados da companhia: a possibilidade de interagir com as publicações através de comentários, e até mesmo trocar likes, aqui conhecido como "curtir".

Durante a reunião entre os funcionários que apresentaram a ideia, a gerência de comunicação, responsável pelo projeto, e a gerência-mãe, o desenho do novo projeto, que não respondia às questões como o gerenciamento da ferramenta, foi refutado já em primeira instância por essa gerência-mãe, que previa antecipadamente a impossibilidade de coordenação do processo que diz respeito à ferramenta e, possivelmente, receava a incompreensão da alta gestão da empresa composta pela diretoria executiva.

\subsubsection{EMPRESA A - ANÁLISE DO CASO}

Considera-se que a comunicação organizacional é um elemento essencial ao entendimento entre os funcionários de uma empresa. Este tipo de comunicação trabalha tanto com notícias que vem de fora de seu ambiente como com situações internas e que interferem, seja de forma positiva ou negativa, em seu progresso e/ou andamento enquanto organização, independentemente do setor em que atua ou mercado ao qual se encontra direcionada. Partindo desta premissa, faz-se relevante todo fator que possa favorecer esta comunicação e, enquanto elemento favorecedor, propostas de melhorias poderiam, ao menos, serem consideradas e analisadas, antes de serem negadas conforme ocorreu no caso em questão.

Outro fator que deve ser amplamente considerado remete ao fato deste novo formato de comunicação ter sido sugerida pelos próprios colaboradores da empresa. Apesar destes colaboradores não disporem de autonomia para a implantação da nova possibilidade e/ou ferramenta de comunicação, eles demonstram ciência de que novas possibilidades de comunicação surgem no horizonte das organizações, e, uma 
vez que a tenham sugerido, certamente sentem necessidade deste tipo de tecnologia e consideram-na como algo que venha a melhorar seu desempenho no trabalho.

Tratando-se especificamente da construção de sentido que deve ser atribuída à comunicação interna de uma organização, apresentada neste estudo com base na narrativa de Guedes (2008), acredita-se que os funcionários que defendem a ampliação e alterações no processo de comunicação interna sentem tal necessidade e, ao reconhecê-la, buscam formas mais elaboradas para a troca de informações e, consequentemente, troca de conhecimentos que venham a favorecer a organização.

Entretanto, como a comunicação entre as esferas que permeiam decisões dentro da organização é falha, não permitindo possibilidades de diálogo amplo e que remeta às alterações, entende-se que ao recusar a proposta, a gerência-mãe não compreendeu, por faltar- Ihe conhecimento técnico específico, que ela poderia ser gerenciada ou ainda, acreditava que faltava mão de obra suficiente para suprir essa necessidade, visto que o projeto não apresentava tais soluções.

Ao apresentar uma proposta como essa, deve-se considerar os elementos que implicam a implantação e o gerenciamento do projeto, nesta ordem. Os principais problemas de gerenciamento interno são como mostrar a eficácia que pode atender às necessidades da empresa e principalmente de seus funcionários e como estabelecer condições modernas que facilitem o relacionamento entre os grupos, influenciando sua produtividade sem negligenciar seu trabalho.

Ainda considerando Guedes (2008), constata-se, por parte da equipe, a necessidade de maior participação no contexto organizacional, para a qual a ferramenta de comunicação faz-

-se essencial. Um indivíduo sente-se mais participativo a partir do momento em que pode expor suas ideias, mesmo que estas não sejam diretamente aceitas e/ou acatadas. 
Essa possibilidade de defesa de um ideal faz parte de indivíduos que buscam interação e valorização dentro de uma equipe de trabalho. Entretanto, conforme observado, a ideia proposta não foi sequer levada aos diretores; e, aquilo que era encarado pela equipe como uma possível solução para a organização empresarial, ou seja, como ferramenta facilitadora, por questão meramente estrutural, não foi considerado.

Atualmente, existem autores que valorizam a possibilidade de troca de informações entre funcionários de uma organização por meio de ferramentas tecnológicas. Como exemplo, conforme observado nos estudos de Carolina Terra (2009), novas tecnologias são utilizadas com frequência como elementos que favorecem e incrementam os canais da comunicação organizacional, e estas ferramentas podem, se bem utilizadas, direcionar a organização para o alcance de seus objetivos. Tratase de um passo evolutivo para a cultura organizacional, por meio do qual a troca de informações relevantes ao ambiente de trabalho e/ou às ações exercidas neste ambiente podem ser facilitadas.

Ao propor maior entrosamento entre as equipes, cria-se um ambiente mais agradável para a realização das tarefas rotineiras, onde os envolvidos acabam dispondo de maior familiaridade uns com os outros. A autora cita as redes sociais como ferramentas que tomaram novas proporções e engajamentos, evoluindo e tornandose efetivas ferramentas corporativas que possibilitam o relacionamento entre os públicos de interesse de uma organização, e que, consequentemente, podem favorecer a comunicação entre os funcionários, assim como o trabalho em si.

Destaca-se também, que apresentar tal proposta sem prever uma mediação/monitoramento pode trazer para a gestão uma ideia de que a interação diferenciada entre os membros da equipe por meio de uma rede, mesmo que interna, pode acarretar em um mal-estar na organização. Com isso, as possibilidades da modernidade tecnológica tornam-se pouco atrativas para aqueles que gerenciam o ambiente de trabalho. 
Nesta premissa, as informações, que inicialmente, foram enviadas, enfrentam um erro estrutural que culmina numa falta de 'abertura' para uma resposta ou mesmo para a construção de um diálogo. O feedback foi perdido, assim como a troca de mensagens em diferentes níveis hierárquicos.

Por meio da comunicação interna são buscadas perspectivas e/ou atitudes participativas, onde, motivado por interesse, a mensagem flui e cria caminhos de mãodupla de acordo com as expectativas. Se este contexto for considerado, quanto mais diversificada e atrativa for a ferramenta usada para a troca de informações, maiores as possibilidades de ação dos envolvidos mediante esta atração e/ou interesse despertados pelo uso da ferramenta.

Baseado nas perspectivas de Terra (2009), que considera a possibilidade de inversão de poderes, constata-se tal possibilidade como elemento intimidador daqueles que se encontram em situação hierarquicamente superior, ou seja, a direção pode ter receio de que outros funcionários adquiram destaque e venham a tecer críticas dentro da organização. Este receio favorece a coibição em relação à proposta de implantação da rede interna.

Complementando esta visão, para Srour (1998), a disputa por autoridade em uma organização faz-se acirrada mediante a percepção da necessidade individual de manutenção do próprio espaço e/ou status. O autor também pontua a necessidade de modernização organizacional, sem que sejam descartadas as tradições, de forma que a comunicação seja um ponto de equilíbrio e não um fator de desavenças e/ou disputas entre funcionários. Kunsch (2008), por sua vez, afirma que o ambiente externo, em constante modernização, exige mudanças de postura interna das organizações para que estas possam acompanhar as mudanças externas. Quando uma organização se fecha às possibilidades de mudanças, um impasse ao progresso já é estabelecido.

Sendo um dos objetivos no processo organizacional, a adaptação de pessoas às suas funções pode gerar influência nos outros, nos ambientes físicos e em si mesmos. A 
possibilidade de mudanças nos processos de comunicação, conforme já citada, pode destacar a opinião sobre um determinado tema e/ou conteúdo e representar ameaça àqueles que se encontram em posição superior.

Conforme explorado na obra de Kissil (1998), citada neste estudo, muitas vezes a mudança é necessária para sobrevivência organizacional. Tomando esta constatação como base, verifica-se que os colaboradores da organização percebem esta mudança como algo positivo, ou seja, como elemento que atuará enquanto ferramenta facilitadora de suas ações, otimizando o trabalho, os rendimentos da organização, e o serviço prestado de modo geral.

Há de se questionar e analisar o (s) motivo (s) que levaram à refutação da proposta apresentada que, essencialmente, disponibilizaria possibilidades de interação com as publicações mediante comentários. Viu-se que, inicialmente, a proposta já foi refutada pela gerência, responsável pela ligação entre funcionários e diretoria, e, desta forma, não chegou até os diretores da empresa.

Observa-se, com base na cultura organizacional da empresa, que uma das possibilidades para esta resposta negativa se dá também por receio dessa gerênciamãe, frente à falta de estruturas gerenciais da ferramenta assim como a falta de conhecimento técnico, possivelmente, receber uma resposta negativa de seus superiores, pelos mesmos motivos, já que a diretoria executiva também não dispõe dessa informação.

Interpretando os fatos, possivelmente, há também falha da gerência responsável ligada à gerência-mãe, assim como do grupo de trabalho que, ao invés de sugerir melhoria na proposta, ou até mesmo incluir melhores informações, acatam a negativa superior por questão meramente cultural.

Se, conforme Castells (1999), a tecnologia é ferramenta matriz de transformações, sejam estas sociais e/ou organizacionais, ao acatar a negativa da possibilidade, sem que esta seja revisitada, confirma-se a estrutura organizacional vigente como baseada 
em cultura inflexível e autocrática, em que prevalece a autoridade hierárquica e os funcionários temem o diálogo.

Também cabe ressaltar que a escolha de um canal de informação a ser utilizado depende da mensagem que será transmitida e do resultado que se deseja alcançar, aliado a gestão do conteúdo. Consequentemente, o medo de arriscar faz também com que a organização empresarial deixe de experimentar uma possibilidade de progresso e faz com que os funcionários, de maneira geral, percam as chances de ter um ambiente de trabalho mais agradável e com uma comunicação interna diversificada e facilitada.

\subsection{DESAFIOS NA ERA DIGITAL}

\subsubsection{EMPRESA B - DESCRIÇÃO DO CASO}

Órgão integrante do Ministério da Saúde, a empresa B surgiu na década de 1930 e atua no desenvolvimento de projetos, estudos, pesquisas e experiências na área da saúde, mantendo acordos internacionais de cooperação e formando redes de conhecimento técnico e científico com o intuito de reduzir o impacto regional e global da doença em que é especializado.

Ao longo das décadas seguintes, sucederam-se vários acontecimentos e conquistas importantes para a história da instituição, como a aquisição de uma sede própria e definitiva, viabilizando-se a criação de um grande hospital-instituto, que possibilita a conquista da posição de órgão referencial para o estabelecimento de parâmetros e para a avaliação da prestação de serviços ao Sistema Único de Saúde (SUS).

Em 2000, buscando expandir a capacidade de seus serviços pelo SUS e garantir uma assistência integral, o Ministério da Saúde regulamenta o projeto responsável para a expansão da oferta de serviços diagnósticos, cirúrgicos, de tratamento e de cuidados paliativos em áreas geográficas antes sem cobertura para a população local. 
Em 2003, uma crise administrativa resulta em mudanças nos processos gerenciais. Sob nova direção, o instituto estabelece um novo modelo de gestão baseado nos princípios da ética, transparência e responsabilidade social, comprometida com as premissas do Sistema Único de Saúde, de universalidade, equidade, integralidade e descentralização, com ampliação da qualidade de acesso aos serviços.

Para marcar os 70 anos de criação da instituição, em 2007, diversas ações e eventos foram realizados ao longo do ano, entre eles destaca-se a divulgação da construção de um moderno centro de desenvolvimento científico e de inovação. O complexo concentrará as áreas de pesquisa, assistência, educação, prevenção, vigilância e detecção precoce da doença tratada pelo hospital-instituto. Desde então, várias etapas vêm sendo cumpridas para concretização do que se convencionou chamar de campus integrado.

A obra se encontra em estágio inicial e sua conclusão está prevista para 2018. Mas, além da construção do novo complexo, foi prevista a manutenção e valorização do atual prédio do instituto. Desde então, outras mudanças e atualizações ocorreram, incluindo a troca do Chefe da Divisão de Comunicação Social.

Com essa mudança importante no setor, muitos processos foram modificados e algumas necessidades identificadas, como a carência de atualização de algumas ferramentas de comunicação que, por conta disso, ganham novos layouts.

No caso da intranet um problema específico foi apontado: era caracterizada como a ferramenta mais impopular entre os funcionários, os quais realizavam acessos obrigatórios, apenas para consultar algum dado específico disponível em sua base. $O$ caráter transmidiático, interativo, tinha se perdido e poucos respondiam às enquetes, que na maioria das vezes eram atualizadas apenas por obrigação, sem qualquer entusiasmo e engajamento.

Como no caso da empresa $A$, a equipe responsável por apresentar uma nova proposta à divisão de comunicação foi a equipe de tecnologia da informação. Baseado na ideia de que já era disponível para os funcionários por meio da plataforma de e-mail uma 
espécie de chat interno, e que a interação entre os funcionários, que conversavam uns com os outros, já era uma realidade, a equipe de TI sugeriu a substituição da intranet por uma rede social, onde os funcionários teriam perfis sociais e poderiam publicar e compartilhar informações sobre os trabalhos exercidos em suas respectivas áreas, adicionando conteúdo ao que usualmente era divulgado.

Durante a reunião de apresentação, a equipe de comunicação, que seria a responsável pelo gerenciamento, inviabilizou a sugestão com inúmeros argumentos. Receavam principalmente o conteúdo que poderia ser difundido. Com essa atitude, pressionaram a gerência-mãe à negativa da proposta, fazendo que se voltasse à proposta inicial de apenas atualizar a ferramenta já existente, a intranet.

\subsubsection{CASO B - ANÁLISE DO CASO}

A equipe de tecnologia apresentou uma proposta de integração de uma plataforma de interação - a intranet - tendo como complemento uma rede social. Também o chat um dispositivo já disponível aos funcionários, favorecia essa interação. Assim, partiuse da premissa de que o relacionamento entre os funcionários não era o problema. Notou-se que a proposta ampliaria e acrescentaria conteúdo àquilo que já existia na cultura organizacional; entretanto, ainda assim, tal proposta foi refutada.

Retoma-se aqui os apontamentos de Srour (1998), autor que ressalta a cultura organizacional como elemento relevante à união dos funcionários em prol dos objetivos comuns à organização. Para este autor, agrupamentos sociais tendem a superestimar padrões de comportamento em detrimento de outros, e tais ações podem representar elementos que dificultam e/ou facilitam mudanças. Sob a ótica do autor, estes processos de mudança podem ser vistos como ameaças.

Ao sugerir a modificação da intranet da organização, considera-se que a equipe de tecnologia buscava elevar a forma de comunicação a outro patamar, além de favorecer interação entre os funcionários com a intenção de beneficiar a organização através desta ferramenta e isto remete diretamente à mudança para a qual, muito provavelmente, a equipe de comunicação ainda não estava devidamente preparada. 
Ainda de acordo com Srour (1998), ao refutar a proposta, o setor responsável pela comunicação dispensou uma oportunidade de "maximizar a aprendizagem" e proporcionar maior troca de experiências entre seus funcionários, encarando tais ações como possíveis ameaças à uma cultura já vigente. O setor de comunicação, que deveria favorecer a aproximação entre os funcionários, agiu de forma contrária.

Para Kunsch (2008), atualmente, a convergência midiática é uma realidade para a maioria das organizações. Percebe-se que grande parte das empresas moderniza-se progressivamente, visando aperfeiçoar a atuação de seus funcionários e, consequentemente, otimizar também sua função frente ao mercado.

Todo este avanço tecnológico é significativo também para os processos de comunicação interna de modo que as pessoas utilizam cada vez mais estas ferramentas como meio de comunicação e interação. A troca de informações e conteúdos através de redes sociais, principalmente entre jovens, é cada vez mais comum.

Considerando estes apontamentos, pode-se constatar que ao propor a integração da intranet a um mecanismo de rede social, buscava-se essa ampliação na comunicação para favorecer, além da socialização, a troca de ideias.

Ainda em Kunsch (2008), destaca-se mais especificamente as transformações possivelmente negativas que o impacto desta rede social poderia trazer para a organização. Ao disponibilizar para o funcionário uma ferramenta de troca de conteúdos, haveria consequentemente, maior liberdade para estas trocas. Nesse tipo de situação, poderia acontecer a troca de conteúdos que não necessariamente fossem de cunho organizacional, ou até mesmo de conteúdos indevidos que viessem a resultar em problemáticas adversas ao ambiente de trabalho.

Para Terra (2009), se não houver um adequado direcionamento do uso deste mecanismo, considerando que as pessoas atualmente o utilizam de maneira ilimitada, há possibilidade de perda de função. Por se tratar de uma organização tradicional, o fato de lidar com a modernidade pode representar um impasse e/ou desafio, situações 
que exigem responsabilidade maior. Este é um dos motivos pelo qual a equipe protestava, receavam que tal responsabilidade pesasse sobre eles, uma vez que toda a demanda comunicacional assim se faz.

Ainda analisando a comunicação como organizada em torno de pessoas, o modelo proposto pelas redes sociais, conforme pontua Terra (2009), tem como 'assuntochave' a confiança. Entretanto, é possível verificar que no caso apresentado esta confiança não foi desenvolvida. O receio em relação à divulgação de conteúdos diversificados ou conteúdo que não estivessem apropriados e/ou direcionados aos objetivos específicos da organização fez com que a proposta de rede social não fosse levada adiante, independente dos benefícios que também poderia representar.

Segundo Terra (2009), o tempo gasto com as redes sociais atualmente é excessivo, e cresce a cada dia, fator que pode também ter sido responsável pela refutação da proposta: pode ter havido receio de que os funcionários dedicassem mais tempo à interação social ilimitada, demandando muitos assuntos paralelos ao interesse corporativo, aquém da capacidade de moderação da equipe.

Ainda assim, caso esta iniciativa tivesse sido aprovada, por se tratar de uma rede social corporativa, voltada para a troca de informações e conteúdo que dizem respeito ao ambiente de trabalho e às funções e tarefas desenvolvidas neste ambiente, a proposta poderia beneficiar à organização, podendo transformar-se em elemento favorável à interação entre a equipe de trabalho e maneira direta para troca de ideias e conteúdos inerentes às tarefas a serem desenvolvidas pelos funcionários.

Tendo em vista a necessidade de modernização das ferramentas de comunicação das empresas atualmente, talvez fosse o caso de a proposta ter sido passada por discussão nas diferentes hierarquias de poder da empresa, em que seriam medidos os prós e os contras e, caso houvesse possibilidade de aprovação, seriam determinados parâmetros específicos para sua utilização e algum controle do conteúdo. Candido e Abreu (2000) ressaltam que os indivíduos apresentam cada vez mais necessidade de interagir, principalmente nos meios digitais. Com base nessa 
necessidade, estes autores comentaram que as redes sociais e a troca de conteúdos através deste meio, vem de encontro à esta necessidade e age de forma a favorecêla.

Nos dias de hoje, os indivíduos têm necessidades diferenciadas de comunicação em comparação à um curto intervalo de tempo passado. Ainda na década passada, não se utilizavam redes sociais com a intensidade e variedade que se usa atualmente.

Partindo desse ponto, é essencial que as empresas modernizem-se e reconheçam que essa realidade tecnológica estará cada vez mais presente em seu cotidiano, seja através de propostas diretas, como a proposta apresentada neste caso, ou por outros meios e/ou necessidades.

Há que se admitir que, assim como outras mídias galgaram seu espaço e reconhecimento, o mesmo vem acontecendo gradativamente com as redes sociais, tornando o uso destas ferramentas cada vez mais recorrente com uma utilidade que se multiplica e atualiza sem parar. Terra (2009) defende que cabe às organizações incentivar as funcionalidades das ferramentas tecnológicas, porém o que se observou foi a coibição em uma situação que poderia ser refletida, pesquisada e adaptada para favorecer a organização.

Ao considerar os apontamentos de Albuquerque (2007), que destaca o público interno como o maior avaliador de uma organização e de seu funcionamento, seria o caso de problematizar o posicionamento dos funcionários responsáveis pelo gerenciamento dos projetos de comunicação frente à negativa recebida. Certamente, esses seriam aqueles que poderiam ter colaborado para a boa impressão que os demais teriam da organização. Mesmo com as alegações de impossibilidade de gerenciamento pela equipe, cabia à gerência responsável levar a situação à diretoria executiva.

Sodré (2002), autor já utilizado neste trabalho, pontua que a sociedade atual busca a modernização e, neste contexto, os processos que recorrem às mídias digitais são fenômenos frequentemente utilizados para tal. A não aceitação da proposta pode apontar uma insegurança nessa modernização. Isto é, há uma ideia que pode elevar 
a organização ao status de mais moderna, entretanto ocorre uma negativa sem que seja feita reflexão sobre as reais possibilidades que podem emergir com a aceitação da proposta ou sua adequação ao contexto da organização.

Castells (1999) e Muniz Sodré (2002) ressaltam que os indivíduos vêm trocando a socialização e interação pessoal, ou seja, frente a frente, pela interação por meio de computadores ou aparelhos semelhantes - aparatos tecnológicos. Desta forma, em termos práticos, a pessoas deixam de se encontrar pessoalmente para compartilhar pensamentos e ações através da internet, usando as redes sociais. Trata-se, segundo os autores, de uma realidade comum e prática à diversos âmbitos da vida humana. $O$ que se observa é que os integrantes das organizações parecem esgueirar-se deste tipo de comportamento.

Este talvez seja fator motivador da tomada de decisão em relação à proposta apresentada pelo setor de tecnologia: manter na organização a estrutura de comunicação adotada até então. Não se trata de uma justificativa, porém, considerando que cada organização é única e defende seus próprios interesses de acordo com sua cultura, é possível que manter-se exatamente como está seja algum tipo de defesa.

Ainda neste contexto, Castells (1999) assevera tecnologia e informação como agentes de transformação. Esta proposta de implementação de rede social corporativa estaria aliando esses dois elementos partindo do pressuposto de que o primeiro seria elemento facilitador do segundo, cabendo ressaltar mais uma vez que isso poderia gerar mudanças para as quais a organização não se encontra ainda preparada ou desafios aos quais a organização não saberia de imediato como responder.

Considerando os impactos que as redes sociais causam nas sociedades, para Castells (1999), haveria também possibilidade de impactar o ambiente de trabalho, ou seja, gerar transformações rápidas e, por ser algo novo, ainda desconhecidas. Lidar com o desconhecido não é tarefa simples e, muito possivelmente, torna-se ainda mais 
complexo dentro de uma estrutura organizacional, influenciando diretamente nas formas de trabalho em uma cultura conservadora.

No caso exposto, portanto, foi analisada a situação na qual a possibilidade de incluir algo novo em uma organização representou um impasse, um desafio que não foi bem visto e sequer considerado pelos demais.

\subsection{ESTRUTURAÇÃO DAS REDES SOCIAIS INTERNAS - PROPOSTA BÁSICA}

Finalmente, considera-se que as possíveis divergências que representam risco sob a ótica dos gestores e/ou executores da proposta receosos com a mudança sejam por causa do fato dos mesmos não conseguirem enxergar os recursos ou a ferramentas proposta como adventos que atuem a favor da comunicação interna. Mesmo frente às variantes tecnológicas disponibilizadas no mercado e acessíveis a todos os âmbitos, as organizações mantém-se conservadoras e primam pela manutenção de suas estruturas conforme estas se encontram.

Tal conservadorismo pode ser oriundo das dificuldades de ver o processo como um todo, conforme discutido anteriormente. Partindo desta premissa, cabe a proposta de uma estrutura básica de gerenciamento, que ultrapasse a ideia embrionária, conforme a disponibilizada abaixo. 
Figura 1 - Proposta básica de estruturação para redes sociais internas
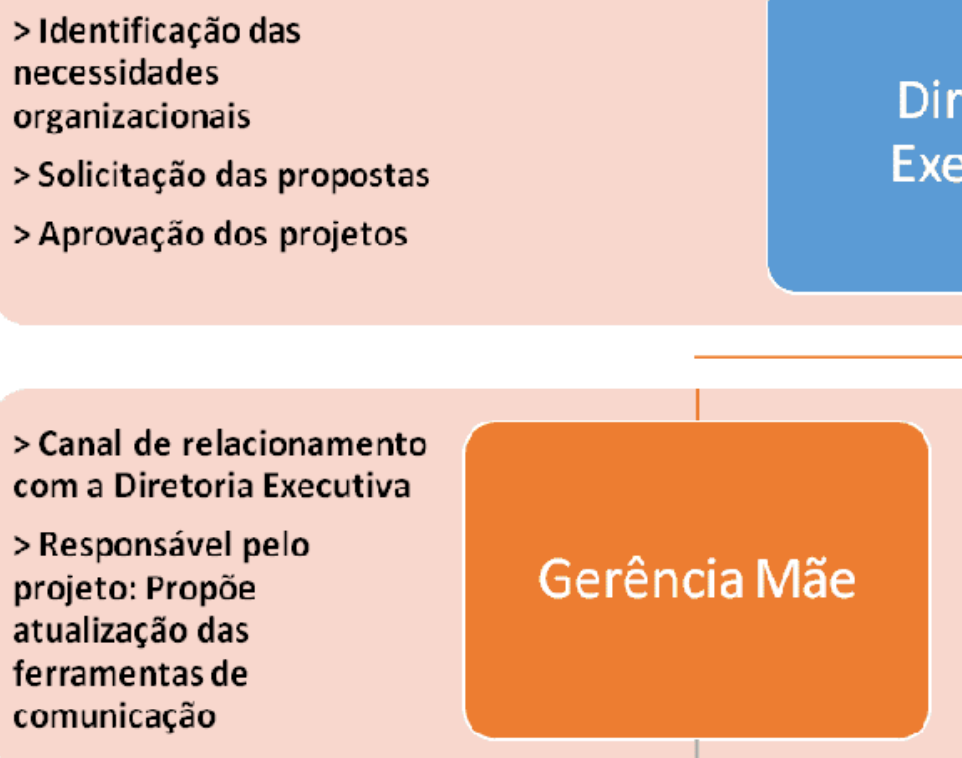

$>$ Responsáveis pelo planejamento e execução: apresentam as propostas, gerenciam e acompanham o planejamento e as etapas.

Nos casos, exemplificados nas áreas de Comunicação e T.I. \\ comunicação}

Diretoria

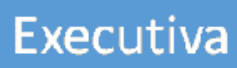

$>$ Propositores e

Executores: Detentores do saber técnico para planejar e executar as propostas.

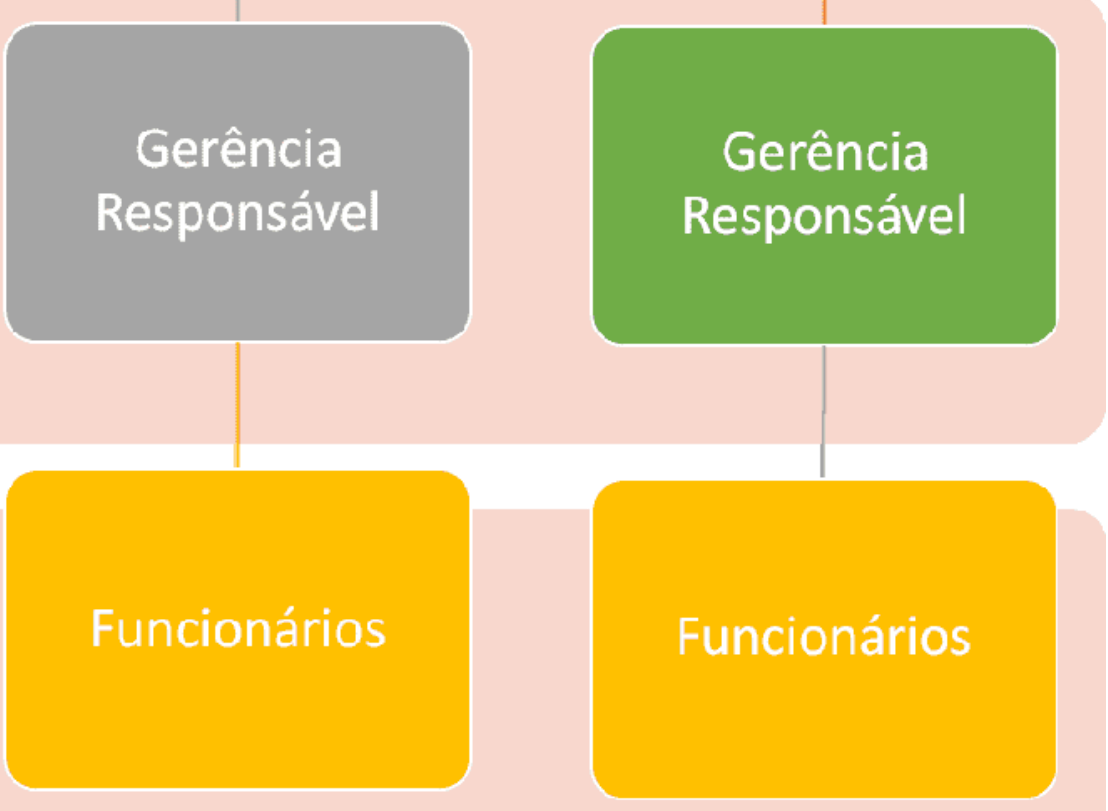

Fonte: A autora, 2015

Neste âmbito, as análises das necessidades que resultaram na proposta de uma rede social corporativa deveriam considerar um minucioso projeto que implica em

Disponível em: https://www.nucleodoconhecimento.com.br/comunicacao/redes-sociais- 
estabelecer uma estrutura mínima responsável por gerir tanto o projeto quanto a ferramenta, observando a descrição das atividades dos envolvidos, formato de interação, forma de acesso, dentre outros processos que devem ser considerados no planejamento e implantação, ou seja, pensando em seu funcionamento e suas implicações.

\section{CONSIDERAÇÕES FINAIS}

\section{CONTRIBUIÇÕES}

O processo de comunicação organizacional deve considerar além das ferramentas tecnológicas também o caráter humano, ou seja, as relações afetivas, emocionais e profissionais que acontecem no âmbito empresarial. Deve-se buscar fornecer, obter e utilizar informações adequadas no momento certo, saber ouvir ou ler opiniões, bem como transmitir com precisão o pensamento.

O desempenho da comunicação interna numa organização é fundamental para seu progresso e, consequentemente, sucesso. Para tal, as estratégias devem ser consideradas, estruturadas e identificadas no ambiente empresarial. A comunicação deve ser tida como relevante por administradores e gestores sempre e não somente em momentos críticos.

Por meio desta pesquisa foi possível verificar alguns posicionamentos negativos em relação às propostas apresentadas por funcionários. Tratam-se de situações que não são incomuns e esbarram em diversas justificativas.

Tratando-se especificamente destes casos, ambos apontam para possibilidades de modernização voltada para a tecnologia, elemento cada vez mais presente no cotidiano dos indivíduos e que interfere na socialização. Ressalva-se que se faz necessário considerar que, para uma organização, modernizar-se não é tarefa simples, visto que envolve inúmeros processos e remete não apenas aos maquinários e suas ferramentas. É preciso readaptar-se ao novo, alterar a cultura organizacional para que esta se enquadre de uma melhor forma no contexto onde se encontra 
inserida, um desafio que pode ser visto como ameaça, no sentido real, em que se teme o novo por acomodação em um determinado padrão, e teme-se o desconhecido por não ter certeza de seus resultados.

A comunicação entre os funcionários é essencial e, se há possibilidades e propostas de melhorias para esta comunicação, por que não, ao menos, tentar? Por que não avaliar tais possibilidades visando adaptá-las à realidade organizacional e respeitando sua cultura ou até mesmo gerenciando sua mudança? Observa-se que as ferramentas de comunicação encontram-se cada vez mais modernas e utilizadas por parcelas enormes da população.

É preciso que as organizações busquem meios de adaptação à realidade que o mundo contemporâneo impõe-lhes, pois esta é forma efetiva de manter-se atuante, com seu produto e/ou serviço no mercado, atendendo aos padrões por este exigidos. Esta obra contribui para evidenciar possíveis erros organizacionais, disponibilizando ao público uma visão primária sobre funcionamento e implicação das ferramentas citadas, exigindo ainda maior aprofundamento técnico.

\section{LIMITAÇÕES DOS CASOS}

É comum que os gestores somente percebam a importância da comunicação em momentos críticos, a partir da constatação de uma ou outra falha. A desconsideração para com a área pode ser uma constante presente no campo de atividade da comunicação organizacional, e, sob esta ótica, muitas empresas deixam de considerar propostas que poderiam oferecer bons resultados, motivados por desvalorização que gera algum tipo de receio.

A busca por capacitação e investimento contínuo por parte das organizações neste setor seria relevante para que se pudesse alcançar a excelência em comunicação organizacional.

Entretanto, cientes de suas responsabilidades e do potencial de suas equipes, cabe aos líderes encontrarem uma melhor maneira de introduzir esses canais de 
comunicação para estimularem suas equipes a irem ao encontro da informação e também, num processo de duas vias, como gestores, devem manter as equipes informadas, e dar-lhes liberdade para que os funcionários possam expressar livremente suas opiniões, sugestões e dúvidas. A partir da apresentação de sugestões, a discussão das mesmas entre funcionários e responsáveis por levar tais sugestões aos superiores é relevante tanto para seu entendimento como também para sua aceitação.

Cabe considerar que cada indivíduo possui um conjunto único e peculiar de interesses, expectativas, aptidões, reações e experiências que interferem diretamente em suas atitudes e em seus pareceres. Isso é levado para os grupos dos quais essa pessoa faz parte. Esse é um dos principais motivos pelos quais as relações interpessoais e a colaboração em um ambiente organizacional nem sempre são fáceis e levam gestores a exigirem um maior equilíbrio entre membros de um grupo visando assegurar seus objetivos e garantir sua sobrevivência.

Por se tratar de estudo específico de apenas dois casos (o que não minimiza sua relevância), o conteúdo e situações aqui apresentados, apesar de comuns em diversos ambientes de trabalho, não podem ser considerados como regra a todas as organizações empresariais.

Em culturas organizacionais mais contemporâneas cujas gerencias e funcionários são compostas por indivíduos que valorizam a liberdade de expressão e a contínua troca de informações, as propostas apresentadas talvez fossem consideradas de maneira diferente, favorecendo os resultados das organizações.

\section{TRABALHOS FUTUROS}

Este estudo foi fundamentado em referencial teórico e apresentou dois casos em que possibilidades diversificadas de comunicação interna foram apresentadas e refutadas por receio/despreparo dos envolvidos. 
Nos casos em questão foram exploradas duas situações diferentes cujos problemas remetiam à má reputação de ferramentas internas interativas digitais, configurando uma delas, exatamente, como uma rede social corporativa.

Frente à impressão geral que se tem sobre redes sociais, sendo estas redes, fontes de compartilhamento dos mais variados assuntos e conteúdos, esta premissa, na análise de gestores, soou como elemento negativo para a organização e que poderia fomentar situações desnecessárias ou que escapavam aos objetivos da organização. Foi possível constatar que, fundamentados em suas próprias opiniões acerca das propostas, os gestores e funcionários optaram por não as executar com os seus superiores.

Considerando que as ferramentas sugeridas nestes casos não foram aceitas, ou seja, não configuraram uma realidade, cabe a sugestão de pesquisas que venham avaliar o emprego de tais ferramentas, verificando as possibilidades que elas poderiam oferecer a uma organização. Uma análise sob esta ótica poderia confirmar a validade de redes sociais internas específicas a determinadas organizações.

Uma pesquisa voltada para empresas que incluíram ferramentas deste tipo em sua cultura organizacional, sendo estas ferramentas sugeridas ou não por seus funcionários, seria interessante como forma de traçar comparações, ou seja, constatar a viabilidade delas e medir seus resultados.

Convém ressaltar que, apesar de ter sido feita uma pesquisa detalhada, considerando sua atualidade e relevância, este estudo não esgotou a temática em questão. Desta forma, demais estudos que remetam e explorem o mesmo tema são bem aceitos nas comunidades científicas e acadêmicas, além de contribuírem para o caráter estratégico da Comunicação Social nas organizações.

\section{REFERÊNCIAS}

ALBUQUERQUE, Milena do Socorro Oliveira. A Contribuição das relações públicas no desenvolvimento da comunicação Interna. In: CONGRESSO BRASILEIRO DE

Disponível em: https://www.nucleodoconhecimento.com.br/comunicacao/redes-sociais- 
CIÊNCIAS DA COMUNICAÇÃO DA REGIÃO, 4., 2007, Belém PA. Intercom Sociedade Brasileira De Estudos Interdisciplinares Da Comunicação. Disponível em: <http://www.intercom.org.br/papers/regionais/norte2007/resumos/R0022-1.pdf> Acesso em: 14 de julho de 2015.

CANDIDO, Gesinaldo; ABREU, Aline. Os conceitos de redes e as relações Interorganizacionais: Um Conceito Exploratório. In: ENCONTRO NACIONAL DE PÓS GRADUAÇÃO EM ADMINISTRAÇÃO - ENANPAD, 24, Florianópolis SC, Anais do $\quad 2000.2$ Disponível em: <http://www.anpad.org.br/diversos/trabalhos/EnANPAD/enanpad_2000/ORG/2000_ ORG783.pdf> Acesso em: 14 de julho de 2015.

CASTELLS, Manuel. A sociedade em rede: a era da informação: economia, sociedade e cultura. São Paulo: Paz e Terra, 1999.

CORRÊA, Elizabeth Saad. A Comunicação Digital nas organizações: tendências e transformações. In: REVISTA BRASILEIRA DE COMUNICAÇÃO ORGANIZACIONAL E RELAÇÕES, São Paulo: ORGANICOM, 2009. Disponível em: <http://revistaorganicom.org.br/sistema/index.php/organicom/article/view/201/301> Acesso em: 14 de julho de 2015.

CURVELLO, João José A. Comunicação Interna e Cultura Organizacional. Brasília: Casa das Musas, 2012.

GUEDES, Ellida Neiva. A comunicação interna como reflexos dos valores contemporâneos. Disponível em: <https://www.academia.edu/771748/A_comunica\%C3\%A7\%C3\%A3o_interna_como _reflex o_dos_valores_contempor\%C3\%A2neos> Acesso em: 14 de julho de 2015.

Já não bastam mídias, campanhas e eventos: a comunicação interna precisa construir sentido. Disponível em <http://www.abrapcorp.org.br/anais2008/gt7_neiva.pdf> Acesso em: 14 de julho de 2015. 
KISSIL, Marco. Gestão da Mudança Organizacional. Série Saúde e Cidadania, vol 4, São Paulo, 1998: Instituto para Desenvolvimento da Saúde / Universidade Federal de São Paulo, Faculdade de Saúde Pública. Disponível em: <http://www.saude.mt.gov.br/arquivo/2951> Acesso em: 14 de julho de 2015.

KUNSCH, Margarida M. Krohling. Comunicação Organizacional na era digital: contextos, percursos e possibilidades. Disponível em: $<$ http://revistas.javeriana.edu.co/index.php/signoypensamiento/article/viewFile/3714/ 3379 > Acesso em: 14 de julho de 2015.

KUNSCH, Margarida M. Krohling (Org.). Gestão Estratégica em Comunicação Organizacional e Relações Públicas. São Caetano do Sul SP: Difusão, 2008.

MARCHIORI, Marlene. Cultura e comunicação organizacional: uma olhar estratégico sobre a organização. 2ed. Revisada e ampliada. São Caetano do Sul SP: Difusão, 2008.

MOREIRA, Elizabeth Huber. PONS, Mônica (Org.). Relações Públicas, tecnologias e públicos. São Caetano do Sul SP: EDUNISC, 2013. E-book

SODRÉ, Muniz. Antropológica do Espelho. Por uma teoria da comunicação linear e em rede. Rio de Janeiro: Vozes, 2002.

SROUR, Robert. Poder, cultura e ética nas organizações. São Paulo: Campus, 1998.

TAPSCOTT, Don. A hora da geração digital: como os jovens que cresceram usando a internet estão mudando tudo, das empresas aos governos. Rio de Janeiro: Agir Negócios, 2010.

TERRA, Carolina. A comunicação organizacional em tempos de redes sociais online e de usuários-mídia. In: CONGRESSO BRASILEIRO DE CIÊNCIAS DA COMUNICAÇÃO DA REGIÃO, 32., 2009, Curitiba PR. Intercom Sociedade Brasileira De Estudos Interdisciplinares Da Comunicação. Disponível em: 
<http://www.intercom.org.br/papers/nacionais/2009/resumos/R4-0495-1.pdf> Acesso em: 14 de julho de 2015.

WOOD JR., Thomaz. Mudança organizacional: uma abordagem preliminar. Revista de Administração de Empresas, São Paulo, 2009. Disponível em: <http://www.scielo.br/pdf/rae/v32n3/a09v32n3> Acesso em: 14 de julho de 2015.

YIN, Roberto K. Estudo de caso: planejamento e métodos. $2^{\mathrm{a}}$ Ed. Porto Alegre: Bookmam. 2001.

\section{APÊNDICE - REFERÊNCIAS DE NOTA DE RODAPÉ}

3. Obra direcionada aos gestores municipais de serviços de saúde, realizada em conjunto com a Faculdade de Saúde Pública da Universidade de São Paulo - USP

4. Grifos do autor. 


\section{FIGURA EM INGLÊS}

Figure 2 - Basic structuring proposal for internal social networks

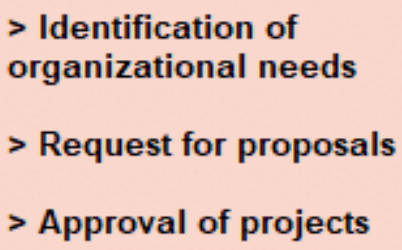

In the cases exemplified in the areas of

Communication and IT

$>$ Proposers and

Executors: Holders of technical knowledge to plan and execute proposals

\section{Executive}

\section{Board}

